\title{
METACOGNITIVE STRATEGIES AND POSSIBILITIES FOR FUTURE RESEARCH
}

\author{
Solange W. Locatelli \\ Federal University of $A B C$, Brazil
}

Basically, metacognition is composed of two central aspects, "knowledge of cognition and regulation of cognition" (Schraw, 1998, p.113), being the last characteristic, fundamental in the teaching and learning of Sciences, since it is desirable that, from the previous knowledge of the students, the possibility of rethinking it, regulating it and, thus, approaching the scientific concepts. Usually, teachers use metacognitive principles in their classes, but they often do so in an unintentional way, which precisely distinguishes a common metacognitive strategy in which, intentionally, moments for reflection and reconstruction are offered to students.

Regarding the regulatory aspect, the metacognitive strategies are promising in assisting learning in science. Schraw (1998) adds that the regulation provided by metacognitive activity may be a skill to be improved with these strategies in a conscious and intentional way by the student.

Since the 1970s, with the first work on metacognition brought by the psychologist John Flavell, there has been an effort and a continuous increase of research in this area, in line with the educational area, for learning purposes.

Some revisions on the theme (Zohar \& Barzilai, 2013, Cleophas \& Francisco, 2018, Lavi, Shwartz, \& Dori, 2019) have brought some limits and possibilities and for future research, the main ones will be mentioned here.

Consensus occurs in the research developed by the three articles cited, which is the fact that metacognition is very important in science education. With regard to the two central aspects, a growing interest lies especially in the regulatory aspect of metacognition in science teaching and learning, that is, to plan classes that encourage, propitiate the selfregulation of the scientific concepts by the students. On the other hand, Zohar and Barzilai (2013) together with Lavi, Shwartaz and Dori (2019) point out that less attention has been paid to the second aspect cited by Schraw (1998), which is metacognitive knowledge. Interestingly, there is a gap of six years between the two review articles, and this aspect is still poorly researched, considering the articles selected for the revisions.

These last two authors also point to a very worrying aspect that indicates few studies in the topic - to the knowledge of teachers and professional development. This is especially important since it recognizes the importance of using metacognitive strategies in science education; however, teachers still have knowledge that needs to be improved in relation to this issue. Cleophas and Francisco (2018) reinforce the difficulty of identifying metacognitive elements in activities developed in the classroom, since they are not always intentionally planned by teachers to be developed in the classroom. In this way, researching on this aspect of professional development could be a priority for the next few years.

Zohar and Barzilai (2013) also point to a lack of research on metacognition in preschool and elementary school, with research being more prevalent considering high school or higher education. This could also be better investigated, as the development of metacognitive abilities occurs in the long term, so the sooner the beginning of the development of this skill, the better. 
One last important aspect pointed out in the research is that despite the effort and the gradual increase of research in this area, there is still a lack of studies regarding the effectiveness of metacognitive instruction (Cleophas \& Francisco, 2018; Zohar \& Barzilai, 2013). This is due to several factors, but one is related to the difficulty of accessing the metacognitive processes demonstrated by students during a classroom activity.

Considering both the research in the area and the experience in the classroom, it is recognized the importance of the use of several metacognitive strategies for the learning of Sciences, including ICT (Information and Communication Technology) (Locatelli, 2018). Thus, limits and possibilities still require intensive investigations, some of which are listed in the course of this text, and are not limited to them, as they are only a few indications.

\section{References}

Cleophas, M. G., Francisco, W. (2018). Metacognição e o ensino e aprendizagem das ciências: uma revisão sistemática da literatura [Metacognition and science teaching and learning: A systematic review of the literature]. Amazônia: Revista de Educação em Ciências e Matemática, 14 (29), 10-26.

Lavi, R., Shwartz, G., \& Dori, Y. D. (2019). Metacognition in chemistry education: A literature review. Israel Journal of Chemistry, 59, 1-15.

Locatelli, S. W. (2018). Information and communication technology (ICT) as a metacognitive strategy for reconstructing science concepts. International Journal on Math, Science and Technology (Finland), 3 (2), 15-27.

Schraw, G. (1998). Promoting general metacognitive awareness. Instructional Science, 26, 113-125.

Zohar, A., Barzilai, S. (2013). A review of research on metacognition in science education: Current and future directions. Studies in Science Education, 49(2), 1-50. https://doi.org/10.1080/03 057267.2013.847261.

Received 10 May 2019; Accepted 28 June 2019

Solange W. Locatelli

PhD, Lecturer, Federal University of ABC, Av. dos Estados, 5001 - Bangú, Santo André - SP, 09210580 Brazil.

E-mail: sol.locatelli@gmail.com

Website: http://ufabc.edu.br/en/

https://scholar.google.com/citations?user=C4iTtHYAAAAJ\&hl=pt-BR 